\title{
The effect of heat treatment on structural and electronic properties of niobium nitride prepared by a thermal diffusion method
}

\author{
Ashraf Hassan Farha ${ }^{1,2^{*}}$, Osman Murat Ozkendir ${ }^{3}$, Hani E. Elsayed-Ali ${ }^{1}$, Ganapati Myneni, ${ }^{4}$ and \\ Yüksel Ufuktepe ${ }^{5 \dagger}$ \\ ${ }^{1}$ Department of Electrical and Computer Engineering and the Applied Research Center, Old Dominion \\ University, Norfolk, Virginia 23529, USA \\ ${ }^{2}$ Department of Physics, Faculty of Science, Ain Shams University, Cairo 11566, EGYPT \\ ${ }^{3}$ Tarsus Technology Faculty, Mersin University, Tarsus 33480 TURKEY \\ ${ }^{4}$ Thomas Jefferson National Accelerator Facility, Newport News, Virginia 23606, USA \\ ${ }^{5}$ Department of Physics, Cukurova University, Adana, 01330, TURKEY
}

\begin{abstract}
Niobium nitride $\left(\mathrm{NbN}_{\mathrm{x}}\right)$ coatings are were prepared onto $\mathrm{Nb}$ substrate by thermal diffusion at high temperatures. The formation of $\mathrm{NbN}_{\mathrm{x}}$ coating by thermal diffusion was studied in the range of $1250-1500{ }^{\circ} \mathrm{C}$ at constant nitrogen background gas pressure $\left(1.3 \times 10^{-3} \mathrm{~Pa}\right)$ and processing time $(180 \mathrm{~min})$. The electronic and crystal structures of the $\mathrm{NbN}_{\mathrm{x}}$ coatings were investigated. It was found that nitrogen diffuses into $\mathrm{Nb}$ forming the $\mathrm{Nb}-\mathrm{N}$ solid solution (bcc) $\alpha$ $\mathrm{NbN}$ phase that starts to appear above $1250{ }^{\circ} \mathrm{C}$. Increasing the processing temperature gives richer $\alpha$-phase concentration. Besides, X-ray absorption spectroscopy (XAS) was performed to study the electronic structure of the $\mathrm{NbN}_{\mathrm{x}}$ layer. The results of the electronic structural study corroborate the crystal structural analysis. The $\mathrm{Nb}_{3,2}$ edge X-ray absorption spectroscopy (XAS) spectrum shows strong temperature dependence. At the highest processing temperature $\left(1500{ }^{\circ} \mathrm{C}\right)$, the number of $d$ holes increased. Nitregen diffusion into $\mathrm{Nb}$ is restling increase electrostatic interaction between $d$ electron and core hole. Electrostatic interaction between $d$ electron and core hole was increased due to nitrogen diffusion into the niobium. For the studied conditions, only the $\alpha-\mathrm{NbN}$ was observed in the $\mathrm{X}$-ray diffraction patterns.
\end{abstract}

Keywords: $\mathrm{NbN}_{\mathrm{x}}$, nitride, surface morphology, XRD, thermal diffusion, XAS.

*Corresponding author: ahass006@odu.edu (Tel.: 00201011917033 ; Fax: 00202-26842123)

†Corresponding author: ufuk@cu.edu.tr (Tel:+90 3223386084 ; Fax: +90 32233860 70) 


\section{Introduction}

Niobium nitride $\left(\mathrm{NbN}_{\mathrm{x}}\right)$ is considered a promising material for many technical and industrial applications. Attractive physical and chemical properties of $\mathrm{NbN}_{\mathrm{x}}$, such as high superconducting transition temperature $\left(T_{c} \sim 17.3 \mathrm{~K}\right)$, strong wear resistance, thermal and chemical stabilities, and high hardness make it useful for many applications. Most of the applications of $\mathrm{NbN}_{\mathrm{x}}$ are related to its superconductivity properties, such as using of $\mathrm{NbN}_{\mathrm{x}}$ layer as a diffusion barrier in Josephson junctions [1,2], coating of superconducting cables, single photon detectors [3], and hot electron bolometers [4,5].

Different preparation methods have been employed to grow $\mathrm{NbN}_{\mathrm{x}}$ thin films, such as metal-organic chemical vapor deposition MOCVD [6], dc and rf sputtering [7,8], ion beam assisted deposition (IBAD) [9], and pulsed laser deposition (PLD) [10,11]. There are different types of substrates that were used for the growth of $\mathrm{NbN}_{\mathrm{x}}$ films. $\mathrm{MgO}$ and sapphire substrates were used for growth of $\mathrm{NbN}_{\mathrm{x}}$ films with $\mathrm{NaCl}$ structure ( $\delta-\mathrm{NbN}$ phase) because of the small lattice mismatch (about 10\%) between these substrates and the $\delta$-NbN phase [12]. Other works were done to prepare $\mathrm{NbN}_{\mathrm{x}}$ films on $\mathrm{Nb}$ substrates for good mechanical properties of the films. In our previous studies, the hexagonal $\beta-\mathrm{Nb}_{2} \mathrm{~N}$ phase showed higher stress and hardness than the cubic $\delta-\mathrm{NbN}$ phase [13]. $\mathrm{NbN}_{\mathrm{x}}$ films grown on $\mathrm{Nb}$ substrates at different PLD conditions were studied for their nanomechanical and crystal structural properties $[13,14]$.

Nitriding of bulk $\mathrm{Nb}$ substrates can be achieved by the so-called reactive diffusion method [15,19] or combustion synthesis [20]. $\mathrm{NbN}_{\mathrm{x}}$ thin films were also produced using rapid thermal processing by heating of $\mathrm{Nb}$ thin films deposited on $\mathrm{Si}$ in molecular nitrogen or ammonia [21,22]. In general, these methods depend on adsorption of nitrogen or ammonia gas at the surface of the $\mathrm{Nb}$ substrate that is heated at high temperatures, then it diffuses into $\mathrm{Nb}$ and forms $\mathrm{NbN}_{\mathrm{x}}$. The treatment of $\mathrm{Nb}$ samples at different conditions (heating temperature, nitrogen background pressure, and heating time and rate) results in samples with diverse properties. The reactive diffusion process has advantages to nitride deposition that include: being less expensive, easy to apply, and covering lager areas, and resulting in a relatively thick nitride with homogenous thickness within a short processing time [17]. Theoretical works predict good performances of $\mathrm{NbN}_{\mathrm{x}}$, if it replaces $\mathrm{Nb}$ in superconducting applications of rf cavities [23]. Several experimental works were done using thermal diffusion method to study the formation of $\mathrm{NbN}_{\mathrm{x}}$ for possible usages in superconducting rf cavities [17, 23-26]. 
Benvenuti et al. [23], studied the formation of niobium nitride by reactive diffusion at $1270-1500{ }^{\circ} \mathrm{C}$ and nitrogen pressure in the range of $10^{3}-10^{5} \mathrm{~Pa}$. In their work, they studied the influence of heating time and nitriding pressure and temperature on the critical phase transition temperatures of the $\mathrm{NbN}_{\mathrm{x}} \beta, \gamma$ and $\delta$ phases. As they reported, applying higher temperatures or longer process times resulted in poorer quality films. Also, nitriding should be carried out at $10^{5}$ $\mathrm{Pa}$ and $1380^{\circ} \mathrm{C}$ or higher for more than 6 min to get higher $T_{c}$ value.

Fabbricatore et al. [24] reported on using nitrogen diffusion at nitrogen pressures and temperature in the range of $10^{4}-3 \times 10^{4} \mathrm{~Pa}$ and $1000-2000{ }^{\circ} \mathrm{C}$, respectively. $\mathrm{NbN}_{\mathrm{x}}$ films with mixed phases were obtained. Temperatures below $1300{ }^{\circ} \mathrm{C}$ gave only the $\beta$ and $\alpha$ phases. The $\gamma$, $\delta$ and $\varepsilon$ phases were identified as the processing temperatures was increased to $1300{ }^{\circ} \mathrm{C}$ and above. Tu et al., [25] reported that thermal diffusion of nitrogen into bulk $\mathrm{Nb}$ at $800{ }^{\circ} \mathrm{C}$ gives samples with surface resistance lower than that of pure $\mathrm{Nb}$ by 2-3 times. To the best of our knowledge, there are no published reports on the diffusion mechanism of nitrogen in $\mathrm{Nb}$ substrate at the lower gas pressure of $1.3 \times 10^{-3} \mathrm{~Pa}$. On the other hand, the mechanisms of nitrogen diffusion into $\mathrm{Nb}$ were reported for conditions forming different $\mathrm{NbN}_{\mathrm{x}}$ phases [17]. Nitrogen diffusion occurs by movement of lattice defects. Nitrogen diffuses in $\mathrm{Nb}$ by vacancy diffusion in both $\gamma$ and $\delta$ niobium nitrides [27,28]. Therefore large concentration of nitrogen vacancies are present in these two phases.

Niobium nitrides with both $\delta$ and $\beta$ phases grown by thermal nitriding in the range of $1100-1900{ }^{\circ} \mathrm{C}$ at $15 \times 10^{4} \mathrm{~Pa}$ were reported [17]. As samples cooled down to less than $1350{ }^{\circ} \mathrm{C}$, the thin layer of the $\delta$ phase transformed into $\gamma, \varepsilon$ and $\delta^{\prime}$ phases. Lengauer et al. [29] reported on high-temperature nitridation of $\mathrm{Nb}$ annealed in high-purity nitrogen at various pressures, times and temperatures below $1400{ }^{\circ} \mathrm{C}$. Phase transformations of $\gamma-\mathrm{Nb}_{4} \mathrm{~N}_{3}$ to $\delta-\mathrm{NbN}$ and $\eta-\mathrm{NbN}$ to $\delta$ $\mathrm{NbN}$ were observed between 1070 and $1300{ }^{\circ} \mathrm{C}$, respectively. In their earlier work, an investigation was performed for the nitrogen pressure range of $10^{3}-3 \times 10^{6} \mathrm{~Pa}$ and temperature range of $1400-1800{ }^{\circ} \mathrm{C}$ [30]. The choice of nitrogen pressure is important for growth rate and homogeneity of the formed $\mathrm{NbN}_{\mathrm{x}}$ phases [30].

Most previous works were done using the thermal diffusion method to find the equilibrium phases and the structural properties of these phases. Also, these works were done at relatively high nitrogen gas pressures to obtain different phases that show high $T_{c}$, such as $\delta$ - 
$\mathrm{NbN}, \gamma-\mathrm{NbN}$ and $\beta-\mathrm{Nb}_{2} \mathrm{~N}$ phases. Phase diagram of $\mathrm{Nb}-\mathrm{N}$ system is very complex and consists of different phases. Up to now several different phase diagrams were proposed $[16,29,30,35]$. The $\alpha-\mathrm{NbN}$ phase is the solid solution of nitrogen in niobium, which is rather less studied and not very well understood. The reaction between niobium and nitrogen is mainly dominated by diffusional transport of nitrogen. The properties of the $\alpha-\mathrm{NbN}$ formed layer can be controlled by the nitrogen pressure and the temperature of the $\mathrm{Nb}$ substrate. Here we study the formation of the $\alpha-\mathrm{NbN}$ solid solution phase by performing experiments at lower nitrogen pressures than previously reported [31]. A series of experiments were performed to investigate the formation and electronic structure of $\mathrm{NbN}_{\mathrm{x}}$ at different temperatures in constant nitrogen pressure using the thermal diffusion method. In the present work we explore the mechanism for formation of $\alpha$ $\mathrm{NbN}$ in the condition of reactive diffusion upon variation in temperature.

\section{Experimental setup}

The $\mathrm{Nb}$ substrates $\left(8 \times 3 \times 0.2 \mathrm{~mm}^{3}\right)$ were etched by the buffered chemical polishing (BCP) method at the same conditions previously used [11]. The samples were kept at $600-650$ ${ }^{\circ} \mathrm{C}$ during the baking of the experimental chamber. During chamber baking, the base pressure was in the mid $10^{-6} \mathrm{~Pa}$.

No heat treatments were done before starting the nitridation of the samples. The thermal nitridation was done at different temperatures ranging from 1250 to $1500{ }^{\circ} \mathrm{C}$ for a period of 180 min. The nitrogen gas was introduced to the chamber through an ultrahigh vacuum (UHV) leak valve to reach the desired pressure in $20-30 \mathrm{sec}$. For samples heated in vacuum lower than $1.3 \times 10^{-5} \mathrm{~Pa}$, no introduction of nitrogen gas into $\mathrm{Nb}$ was done. Tungsten wire heater-baskets were used for sample heating. The sample temperature was measured by a pyrometer (IGA 15 plus, Mikron Infrared Inc.). When the desired time for nitridation was reached, the UHV valve was opened and the power supplied to the sample heater was turned off simultaneously to allow the sample to cool down in the vacuum to room temperature before removal from the UHV chamber.

XRD measurements were done using Bruker-AXS three-circle diffractometer. A Bruker SMART APEX II instrument is equipped with graphite-monochromated $\mathrm{CuK}_{\alpha}$ radiation and a SMART Apex II CCD detector. X-ray source of wavelength of $1.5406 \AA$ ( $\mathrm{Cu}-\mathrm{K} \alpha$ line) is fixed

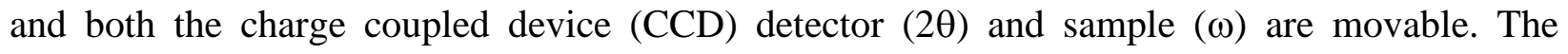


detector $(2 \theta)$ is covering about $30^{\circ}$ per image position. Three image positions were used for the experiment. In each case, the angle $2 \theta$ is the center position of the $30^{\circ} \mathrm{CCD}$ image, and each value is set so that the angles of incidence and diffraction are equal. Two-dimensional (2D) XRD images are recorded on diffraction patterns of each sample.

The X-ray absorption near edge structure (XANES) measurements were performed on beamline 8.2 at the Stanford Synchrotron Radiation Lightsource in the SLAC National Accelerator Laboratory. The total electron yield (TEY) mode was used for XANES measurements by measuring sample current. The current measurements were done using a low noise preamplifier (Stanford research system Model SR570). The beam flux $\left(I_{o}\right)$ signal from a gold grid was used to normalize the spectra. The base pressure of the XANES chamber during the experiment was about $2.0 \times 10^{-7} \mathrm{~Pa}$.

\section{Results and discussion}

Figure 1 shows the XRD of niobium nitride coatings fabricated by heating the $\mathrm{Nb}$ substrate at different temperatures in constant nitrogen pressure $\left(1.3 \times 10^{-3} \mathrm{~Pa}\right)$ for $180 \mathrm{~min}$. processing time. The XRD pattern of the unheated $\mathrm{Nb}$ substrate is also included in Fig. 1 as a reference.

\section{Figure 1}

XRD patterns show no clear evidence of nitridation for samples processed at temperature ranging from 1250 to $1500{ }^{\circ} \mathrm{C}$, because the most highest $\mathrm{XRD}$ peaks of both $\mathrm{Nb}$ and $\alpha-\mathrm{NbN}$ are at the same $2 \theta$ values [32,33]. For a more detail view of the XRD patterns, the 2D-XRD images of the samples were recorded and are shown in Figure 2. Using 2D-XRD images makes XRD a good tool for phase identification of the crystal orientation of the samples [34]. The 2D-XRD of the $\mathrm{Nb}$ substrate in Figure 2 shows a strong spot at $2 \theta=69.52^{\circ}$, which is an indication of dominant orientation in $\mathrm{Nb}(211)$ direction. As samples were heated to $1250{ }^{\circ} \mathrm{C}$, fine grains with 
strong texture were formed. The size of the grains gets smaller as the temperature increases which is indicated by the formation of spotty rings at $1500{ }^{\circ} \mathrm{C}$.

According to the $\mathrm{Nb}-\mathrm{N}$ phase diagram, diffusion of the nitrogen through the surface initially forms the bcc $\alpha-\mathrm{NbN}$ phase $[15,16]$. In the present experiment, the maximum amount of nitrogen diffused into the $\mathrm{Nb}$ substrate at a temperature of $1500{ }^{\circ} \mathrm{C}$. Therefore, at that temperature we observe the highest largest lattice constant.

Figure 2

Figure 3

The calculated average crystallite size using the Scherrer equation and lattice constants of the $\alpha-\mathrm{NbN}$ from XRD patterns are shown in Figure 3. The error bars in Fig. 3 represent the values of the standard deviation for calculation of different diffraction planes in XRD patterns. The obtained average lattice parameter of the highest three XRD peaks in Fig. $1(\mathrm{Nb}(110)$, $\mathrm{Nb}(200)$, and $\mathrm{Nb}(211)$ ) are higher than that of the unheated $\mathrm{Nb}$ substrate (3.294 $\AA$ ). The increase in the lattice constant with increasing nitrogen content in $\mathrm{Nb}$ agrees well with the result given by Taylor and Dole [35,36]. It also confirms the formation of the $\alpha-\mathrm{NbN}$ phase in our samples. The lattice constant of $\mathrm{Nb}$ is increased due to dissolving nitrogen in niobium. It has been shown that the lattice parameter of $\mathrm{a}=3.294 \AA$ for pure $\mathrm{Nb}$ increases to $3.306 \AA$ at 1.05 atomic $\%$ diffusion өf nitrogen [35]. As observed in Fig. 3, if the temperature is raised, crystallite size of $\alpha-\mathrm{NbN}$ increases as a result of more nitrogen dissolving in $\mathrm{Nb}$. Therefore, we can conclude that nitrogen dissolves within the grains and in the grain boundaries.

\section{Figure 4}

The $\alpha-\mathrm{NbN}$ phase content was obtained by using the integrating area under the each related XRD peaks in Fig.1. The $\alpha-\mathrm{NbN}$ phase concentration was calculated as the ratio of the sum of the intensities of the $\alpha-\mathrm{NbN}$ peaks divided by the total intensities of all XRD peaks. The effect of the processing temperature on the concentration of the $\alpha-\mathrm{NbN}$ is shown in Fig. 4. The 
solid curve in the figure shows the result of the best fit to the exponential function $\left(y=y_{0}+\right.$ $\left.A_{1} e^{x / t_{1}}\right)$. This shows that, in the studied range of temperature and constant background pressure, the $\alpha-\mathrm{NbN}$ phase concentration in $\mathrm{Nb}$ follows an exponential growth with temperature.

XANES is considered as a powerful tool to investigate the electronic and atomic structures of materials [37]. The total electron yield (TEY) detection is commonly used to record spectra of XANES. We used TEY mode to record the sample signal which was monitored by the drain current through the sample, and then the measured sample current was normalized to incoming photon flux. Fig. 5(a) shows XANES spectra for $\mathrm{Nb} \mathrm{M}_{3,2}$ edge while Fig. 5(b) is the measured branching ratio of the intensity, both as a function of heating temperature.

\section{Figure 5}

The $\mathrm{Nb} \mathrm{M}_{2,3}$ edges are attributed to the transition of $\mathrm{Nb} 3 p$ electrons to unoccupied $4 d$ and $5 s$ states. The two peaks at about 365.5 and $380.5 \mathrm{eV}$ can be assigned to the $\mathrm{Nb} 3 p_{3 / 2}$ and $3 p_{1 / 2}$, respectively. The peak at $365.5 \mathrm{eV}$ is stronger than that at $380.5 \mathrm{eV}$. The intensity of nitrogen K-edge peak at $406.5 \mathrm{eV}$ did not show any noticeable alteration with changes in the heating temperature.

The branching ratio (BR) is defined as the intensity ratio of $I\left(M_{3}\right) /\left[I\left(M_{2}\right)+I\left(M_{3}\right)\right]$ where $I\left(M_{3}\right)$ and $I\left(M_{2}\right)$ are the measured area under the $M_{3}(j=3 / 2)$ and $M_{2}(j=1 / 2)$ peaks, respectively, and which is proportional to the oscillator strength of the $3 p-4 d$ and/or $3 p-5 s$ states spin-orbit interactions. The $\mathrm{BR}$ is changed significantly from 0.615 to 0.650 as the processing temperature was increased from 1250 to $1500{ }^{\circ} \mathrm{C}$. Fig. 4(b) shows that the electronic structure changes a little for samples processed above $1400{ }^{\circ} \mathrm{C}$ compared to samples processed below that temperature. For samples processed at 1400 and $1500{ }^{\circ} \mathrm{C}$, the branching ratio was almost similar. This result is consistent with the findings in Fig. 3 that the lattice parameter did not change much after 1400 ${ }^{\circ} \mathrm{C}$. The change in the BR intensity indicates a changes in the coordination of the $\mathrm{Nb}$ and $\mathrm{N}$ atom with increasing $\alpha-\mathrm{NbN}$ phase concentration. Furthermore, the BR is found to be strongly dependent on the local chemical environment. This can be explained by higher processing temperature resulting in more nitrogen incorporation into niobium which increases hybridization 
between the $\mathrm{Nb} 4 d$ and $\mathrm{N} 2 p$ levels. Larger covalent contribution to the $\mathrm{Nb}-\mathrm{N}$ bonding enhances the strong $3 p-4 d$ Coulomb interaction leading to strong BR. Higher temperature samples resulted in higher electron-core-hole interaction and the number of $d$ final states available.

\section{Conclusion}

Thermal diffusion of nitrogen into $\mathrm{Nb}$ forming the $\alpha-\mathrm{NbN}$ phase was studied. The samples were heated for $180 \mathrm{~min}$ at different temperatures $\left(1250-1500{ }^{\circ} \mathrm{C}\right)$ and constant $1.3 \times 10^{-3}$ $\mathrm{Pa}$ nitrogen pressure. In 2D-XRD images show the formation $\alpha-\mathrm{NbN}$ grains. From the ring shape, the grains become smaller as the temperature is increased to $1500{ }^{\circ} \mathrm{C}$. This observation is consistent with the crystallite size calculated using the Scherrer relation. The average crystallite size decreases from $\sim 21.4 \mathrm{~nm}$ at $1250{ }^{\circ} \mathrm{C}$ to $\sim 17.6 \mathrm{~nm}$ at $1500{ }^{\circ} \mathrm{C}$. The calculated lattice constants from the three $\mathrm{Nb}$ peaks with highest intensity showed transformation from decreasing to increasing as the temperature is raised from 1250 to $1500{ }^{\circ} \mathrm{C}$. The present results indicate that the most favorable temperature for the formation of the $\alpha-\mathrm{NbN}$ phase by heat treatment is 1400 $1500{ }^{\circ} \mathrm{C}$ at $1.3 \times 10^{-3} \mathrm{~Pa}$ nitrogen pressure. Furthermore, from XANES measurements for the $\mathrm{Nb}$ $\mathrm{M}_{2,3}$ edge, we found that at the higher processing temperature of $1500{ }^{\circ} \mathrm{C}$, the number of $d$ holes increased, and as a result the spin-orbit interaction also increased yielding higher branching ratio values at the $\mathrm{M}$ edge. We observed only the formation of $\alpha-\mathrm{NbN}$ phase in the studied temperature and background nitrogen pressure range. Different gas pressure and temperature ranges results in the formation of different $\mathrm{NbN}_{\mathrm{x}}$ phases and morphologies [31].

The amount of dissolved nitrogen in niobium $x$ in at.\% can be expressed by the equation [35]:

$$
x=A \sqrt{P_{N 2}} \exp \left(\Delta H_{N} / R T\right)
$$

Where $A$ is constant, $P_{N 2}$ is the pressure of nitrogen, $\Delta H_{N}$ is the heat of solution of nitrogen in the $\alpha-\mathrm{NbN}$ phase, $R$ is the gas constant and $T$ is temperature. The equilibrium concentration of nitrogen in niobium is related to the processing temperature and background nitrogen gas pressure. A summary of the different $\mathrm{Nb}-\mathrm{N}$ phases for different nitrogen incorporation in $\mathrm{Nb}$ is given in Ref. 35. It was revealed that only the $\alpha-\mathrm{NbN}$ is formed for our experimental conditions. The XRD patterns obtained clearly indicate that only the $\alpha-\mathrm{NbN}$ phase is present and no 
transformation to another $\mathrm{NbN}_{\mathrm{x}}$ phases is observed. The $\alpha-\mathrm{NbN}$ phase is identified by its body centered cubic (bcc) structure, similar to $\mathrm{Nb}$ but with increase lattice parameter due to nitrogen incorporation. For the experimental conditions in the present study, the XRD patterns did not show the formation of the hexagonal closed packed (hcp) $\mathrm{Nb}_{2} \mathrm{~N}$, the tetragonal $\mathrm{NbN}$, or any of the other known $\mathrm{Nb}-\mathrm{N}$ structures.

\section{Acknowledgments}

A. H. F. was supported by a scholarship from the Egyptian Ministry of Higher Education and a Jefferson Lab scholarship funded by the Department of Energy Office of Nuclear Physics ARRA-NPQ project at Jefferson Lab under the U.S. DOE Contract No. DE-AC05-06OR23177.

The authors are grateful to the Stanford Synchrotron Radiation Light source (SSRL), California, USA, for providing synchrotron-based XAS facility. Use of SSRL source is supported by the US Department of Energy, Office of Basic Energy Sciences, under Contract No. DEAC0276SF00515. Support of DOE Cooperative Research Program for SESAME project is acknowledged by A.H.F., O.M.O. and Y.U.

\section{References}

[1] M. Radparvar, Cryogenics, 35 (1995) 535-540.

[2] M. Lucci, H.N. Thanh, I. Davoli, Superlattices and Microstructures, 43 (2008) 518-523.

[3] R. Sobolewski, A. Verevkin, G.N. Gol'tsman, A. Lipatov, K. Wilsher, IEEE Transactions on Applied Superconductivity, 13 (2003) 1151-1157.

[4] S. Miki, Y. Uzawa, A. Kawakami, Z. Wang, Electronics and Communications in Japan (Part II: Electronics), 85 (2002) 77-83.

[5] A.D. Semenov, H.W. Hubers, IEEE Transactions on Applied Superconductivity, 11 (2001) 196-199.

[6] D. Bekermann, D. Barreca, A. Gasparotto, H.W. Becker, R.A. Fischer, A. Devi, Surface and Coatings Technology, 204 (2009) 404-409.

[7] B. Abdo, E. Arbel-Segev, O. Shtempluck, E. Buks, IEEE Transactions on Applied Superconductivity, 16 (2006) 1976-1987.

[8] E.J. Cukauskas, W.L. Carter, S.B. Qadri, Journal of Applied Physics, 57 (1985) 2538-2542. 
[9] Y. Gotoh, M. Nagao, T. Ura, H. Tsuji, J. Ishikawa, Nuclear Instruments and Methods in Physics Research Section B: Beam Interactions with Materials and Atoms, 148 (1999) 925-929. [10] A.H. Farha, A.O. Er, Y. Ufuktepe, G. Myneni, H.E. Elsayed-Ali, Surface \& Coatings Technology, 206 (2011) 1168-1174.

[11] A.H. Farha, A.O. Er, Y. Ufuktepe, H.E. Elsayed-Ali, Materials Chemistry and Physics, 132 (2012) 667-672.

[12] R.E.d. Lamaestre, P. Odier, J.-C. Villegier, Applied Physics Letters, 91 (2007) 232501232503.

[13] M.A. Al Mamun, A.H. Farha, Y. Ufuktepe, H.E. Elsayed-Ali, A.A. Elmustafa, Journal of Materials Research, 27 (2012) 1725-1731.

[14] M.A. Mamun, A.H. Farha, A.O. Er, Y. Ufuktepe, D. Gu, H.E. Elsayed-Ali, A.A. Elmustafa, Applied Surface Science, 258 (2012) 4308-4313.

[15] H. Bauer, Journal of Low Temperature Physics, 24 (1976) 219-227.

[16] G. Brauer, Journal of the Less Common Metals, 2 (1960) 131-137.

[17] R. Musenich, P. Fabbricatore, G. Gemme, R. Parodi, M. Viviani, B. Zhang, V. Buscaglia, C. Bottino, Journal of Alloys and Compounds, 209 (1994) 319-328.

[18] A.V. Linde, R.M. Marin-Ayral, D. Granier, F. Bosc-Rouessac, V.V. Grachev, Materials Research Bulletin, 44 (2009) 1025-1030.

[19] A.V. Linde, V.V. Grachev, R.M. Marin-Ayral, Chemical Engineering Journal, 155 (2009) $542-547$.

[20] V. Buscaglia, F. Caracciolo, M. Ferretti, M. Minguzzi, R. Musenich, Journal of Alloys and Compounds, 266 (1998) 201-206.

[21] C. Angelkort, H. Lewalter, P. Warbichler, F. Hofer, W. Bock, B.O. Kolbesen, Spectrochimica Acta Part A: Molecular and Biomolecular Spectroscopy, 57 (2001) 2077-2089.

[22] A. Berendes, O. Brunkahl, C. Angelkort, W. Bock, F. Hofer, P. Warbichler, B.O. Kolbesen, Analytical and Bioanalytical Chemistry, 379 (2004) 554-567.

[23] C. Benvenuti, P. Chiggiato, L. Parrini, R. Russo, Nuclear Instruments and Methods in Physics Research Section A: Accelerators, Spectrometers, Detectors and Associated Equipment, 336 (1993) 16-22.

[24] P. Fabbricatore, G. Gemme, R. Musenich, R. Parodi, M. Viviani, B. Zhang, V. Buscaglia, IEEE Transactions on Applied Superconductivity, 3 (1993) 1761-1764. 
[25] M. Pham Tu, K. Mbaye, L. Wartski, J. Halbritter, Journal of Applied Physics, 63 (1988) 4586-4590.

[26] G. Gemme, P. Fabbricatore, R. Musenich, R. Parodi, T. Rossi, M. Viviani, B. Zhang, Journal of Applied Physics, 77 (1995) 257-264.

[27] S.J. Kim, H.F. Franzen, Journal of the Less Common Metals, 143 (1988) 339-343.

[28] G. Heger, O. Baumgartner, Journal of Physics C: Solid State Physics, 13 (1980) 5833.

[29] W. Lengauer, M. Bohn, B. Wollein, K. Lisak, Acta Materialia, 48 (2000) 2633-2638.

[30] M. Joguet, W. Lengauer, M. Bohn, J. Bauer, Journal of Alloys and Compounds, 269 (1998) 233-237.

[31] Y. Ufuktepe, A.H. Farha, S.-i. Kimura, T. Hajiri, F. Karadağ, Md A. Al Mamun, A. A. Elmustafa, G. Myneni, and H.E. Elsayed-Ali, Mater. Chem. Phys. 141, 393-400 (2013).

[32] I.C.f.D. Data, in: Powder Diffraction File 00-035-0789, 2004.

[33] I.C.f.D. Data, in: Powder Diffraction File 00-043-1420, 2004.

[34] B.B. He, Two-dimensional X-Ray Diffraction, Wiley-Interscience, Hoboken, USA, 2009.

[35] A. Taylor, N.J. Doyle, Journal of the Less Common Metals, 13 (1967) 399-412.

[36] A. Taylor, N.J. Doyle, Journal of the Less Common Metals, 13 (1967) 413-430.

[37] N. Schonberg, Acta Chemica Scandinavica, 8 (1954) 208-212. 


\section{Figure captions:}

Figure 1: XRD patterns of unheated $\mathrm{Nb}$ substrate and heat-treated $\mathrm{Nb}$ at the temperatures between 1250 and $1500{ }^{\circ} \mathrm{C}$ for $180 \mathrm{~min}$ in $1.3 \times 10^{-3} \mathrm{~Pa}$ nitrogen background pressure.

Figure 2: 2D-XRD patterns of unheated $\mathrm{Nb}$ substrate and heat-treated $\mathrm{Nb}$ at temperatures between 1250 and $1500{ }^{\circ} \mathrm{C}$ for $180 \mathrm{~min}$ in $1.3 \times 10^{-3} \mathrm{~Pa}$ background nitrogen pressure.

Figure 3: Variation of mean crystallite size and lattice parameter with temperature calculated from Fig. 1.

Figure 4: Influence of the heat treatment on concentration of the $\alpha-\mathrm{NbN}$ cubic phase. The solid line is curve-fit to experimental data.

Figure 5: XANES spectra of $\mathrm{NbN}_{\mathrm{x}}$ at the $\mathrm{Nb} \mathrm{M}_{3,2}$ edge region as a function of processing temperatures (a) and branching ratio of the peak intensities at the $\mathrm{M}_{3,2}$-edge as a function of processing temperature. The drawn line serves only guide the eye (b). 


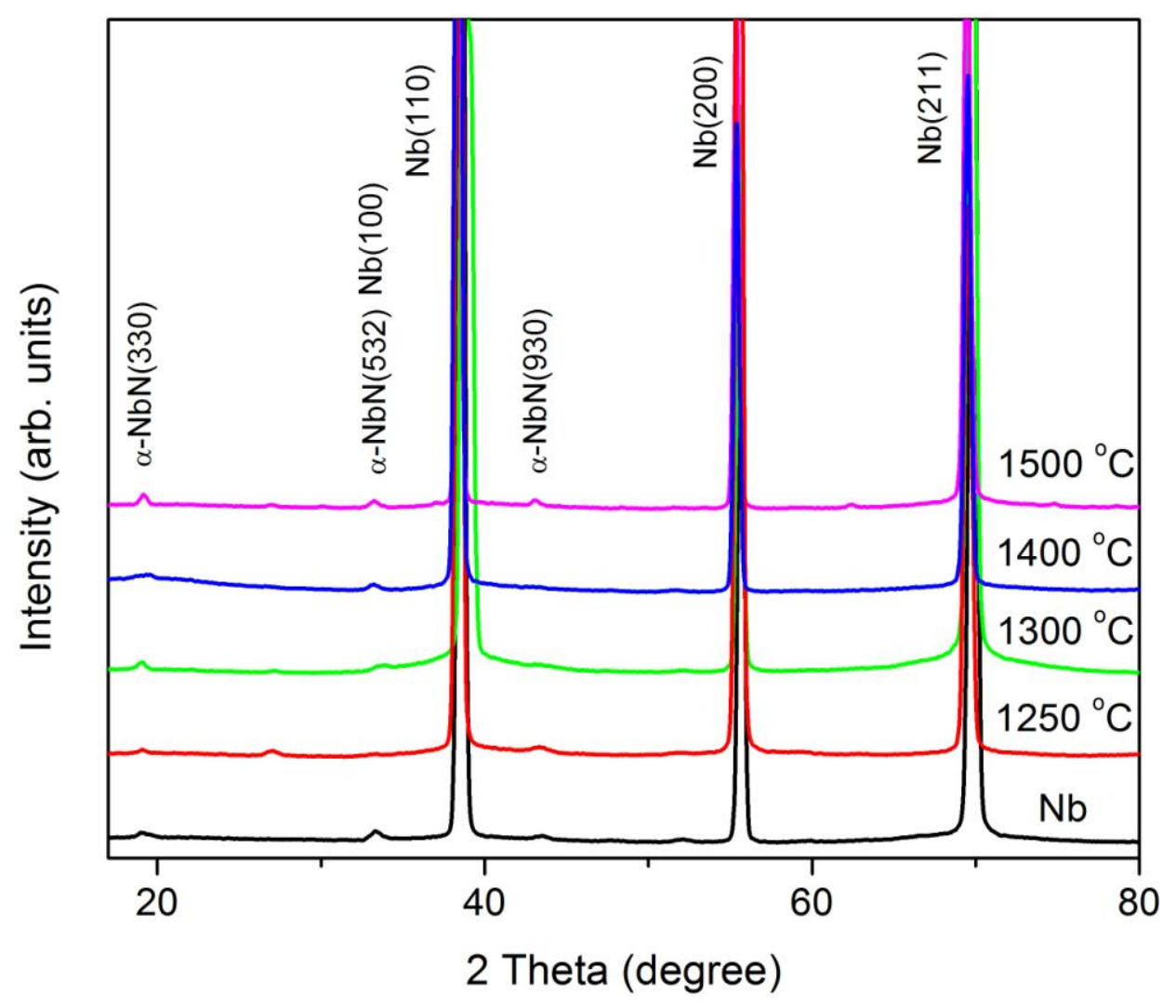




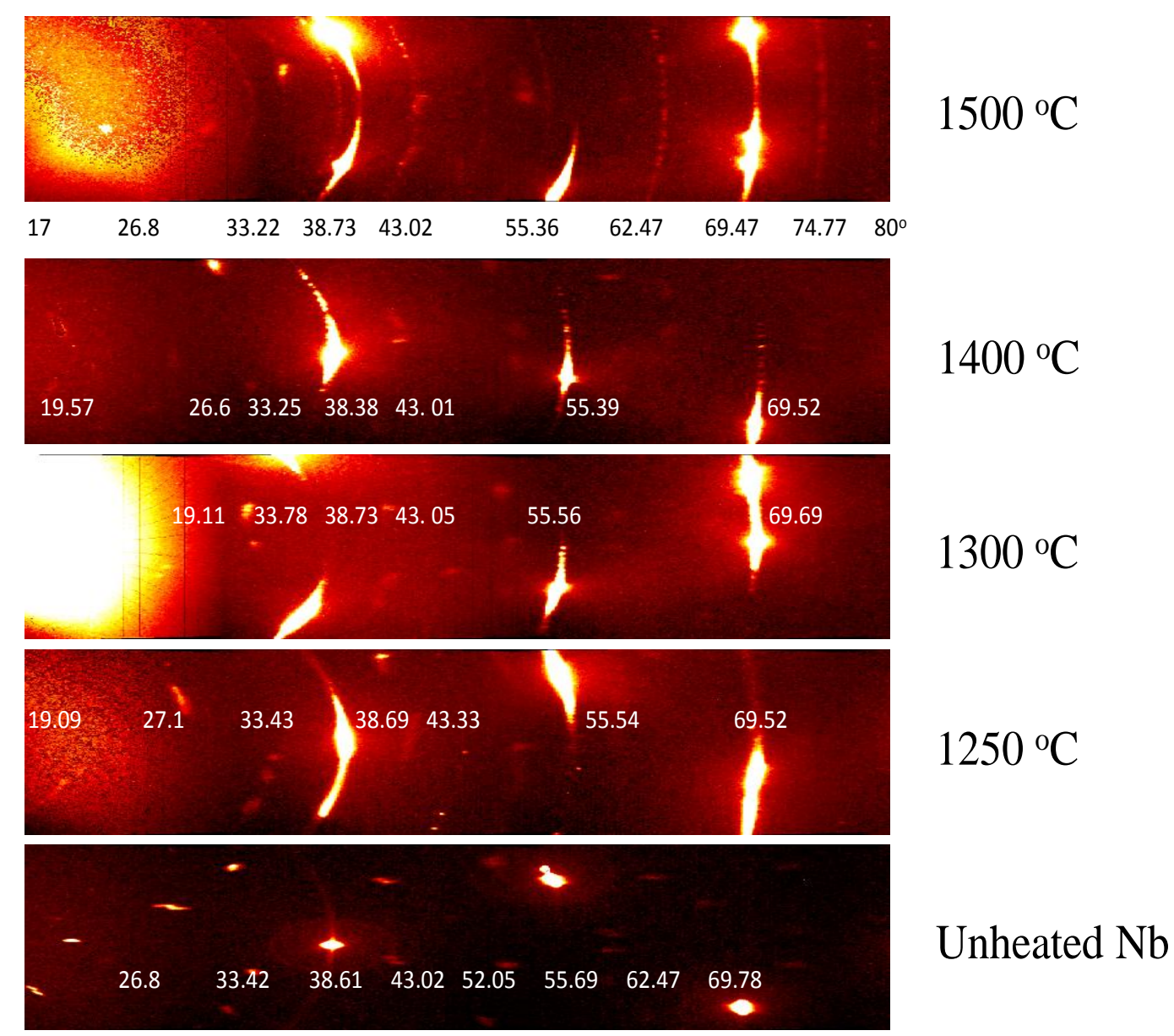




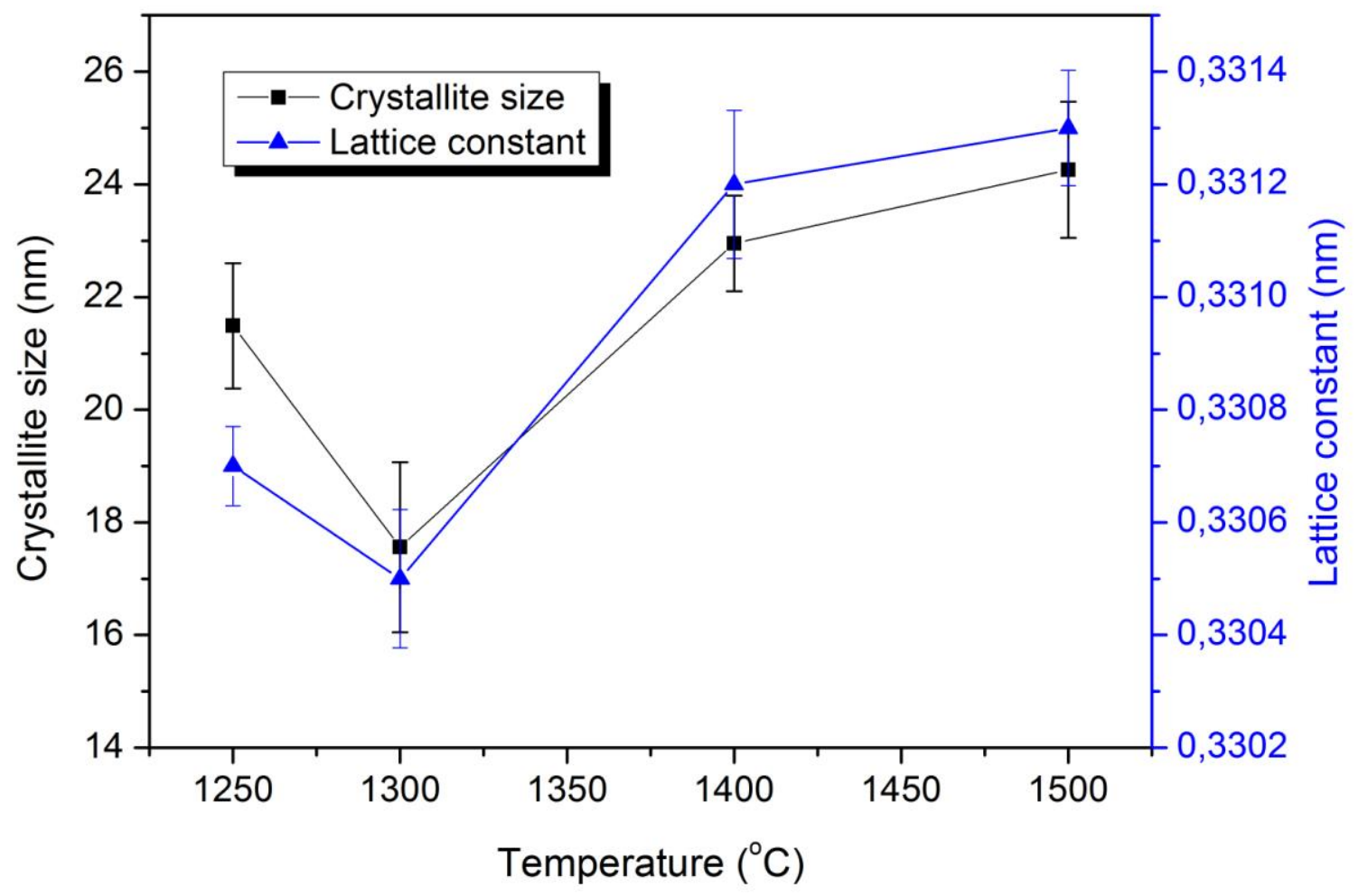




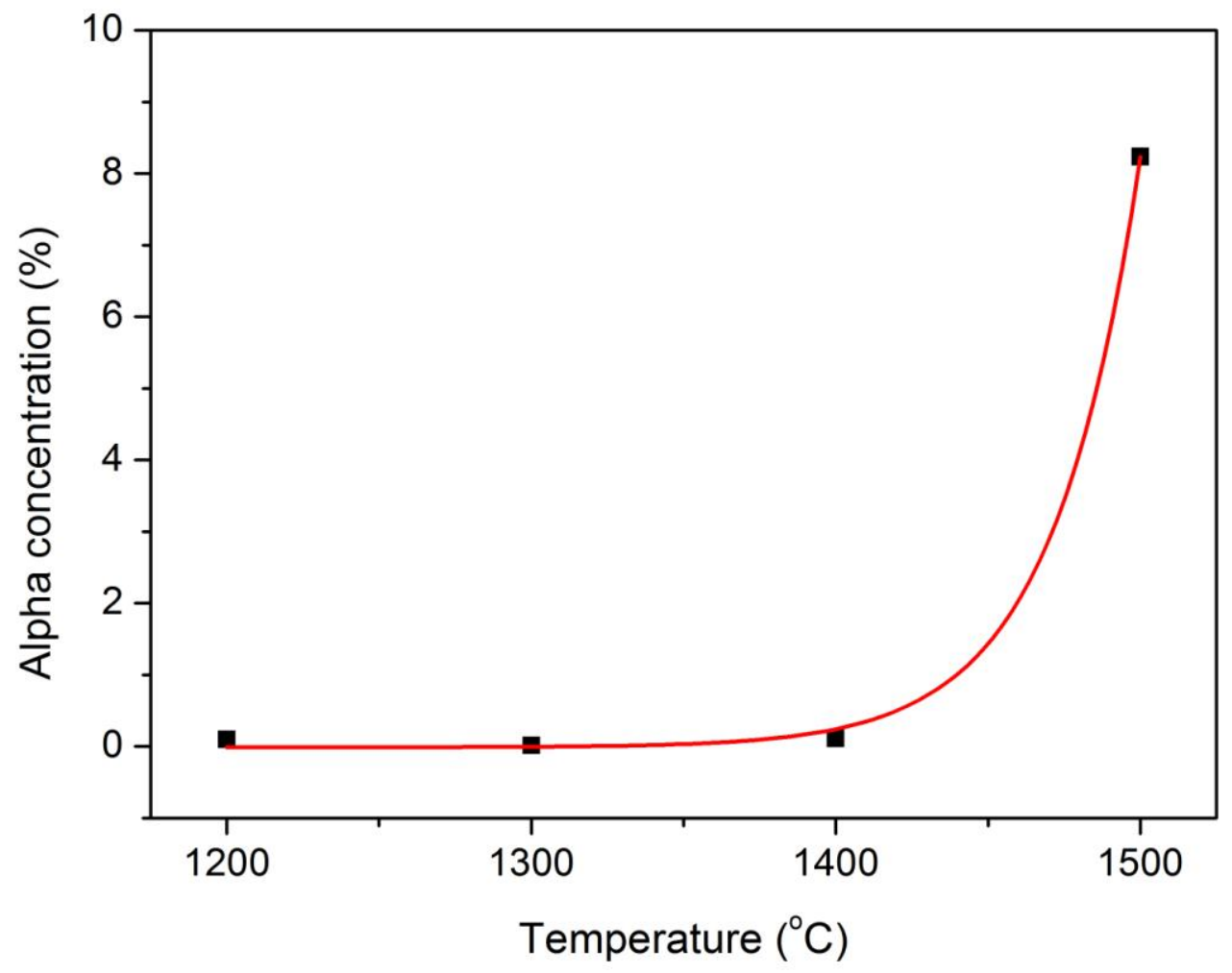




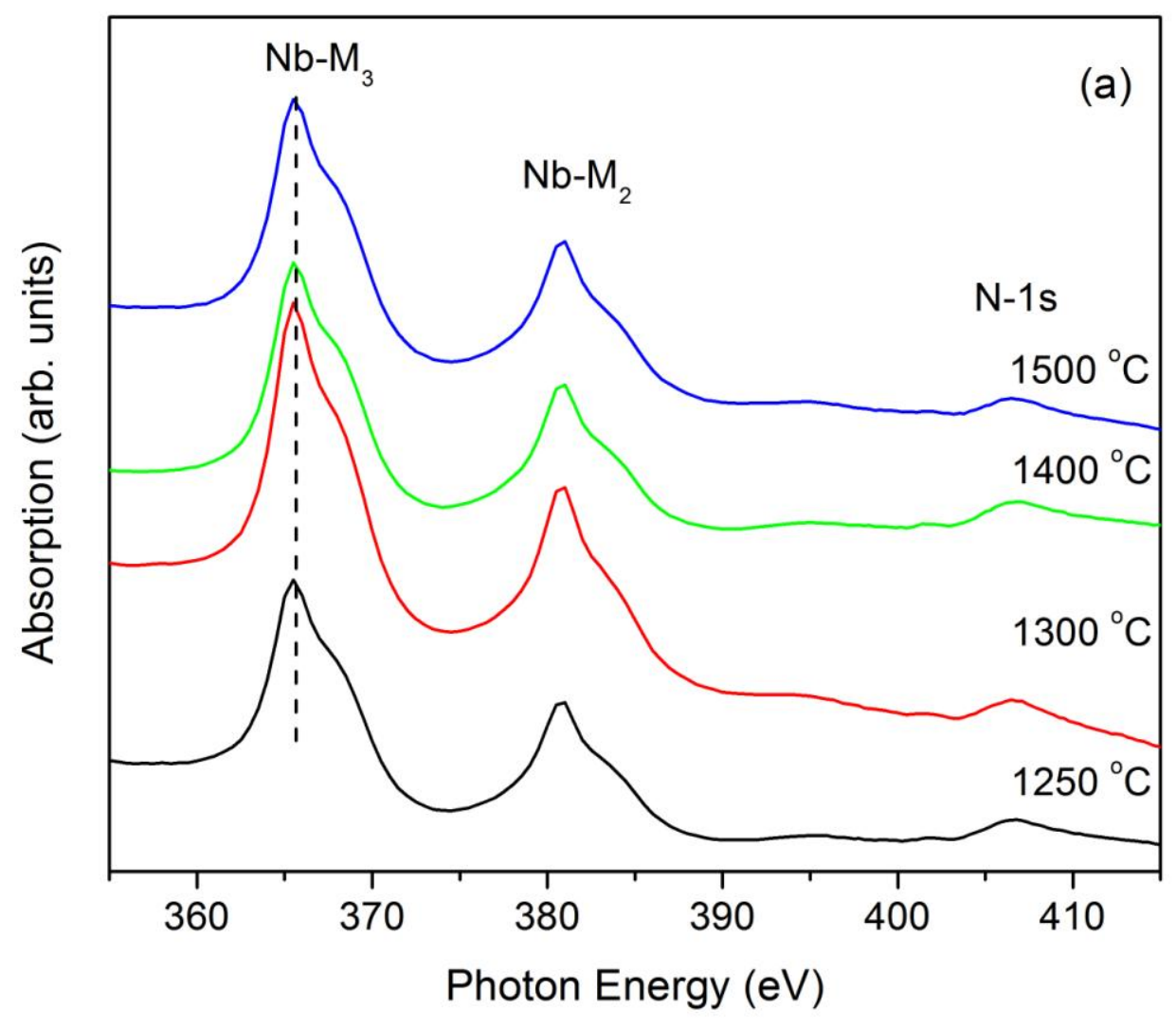




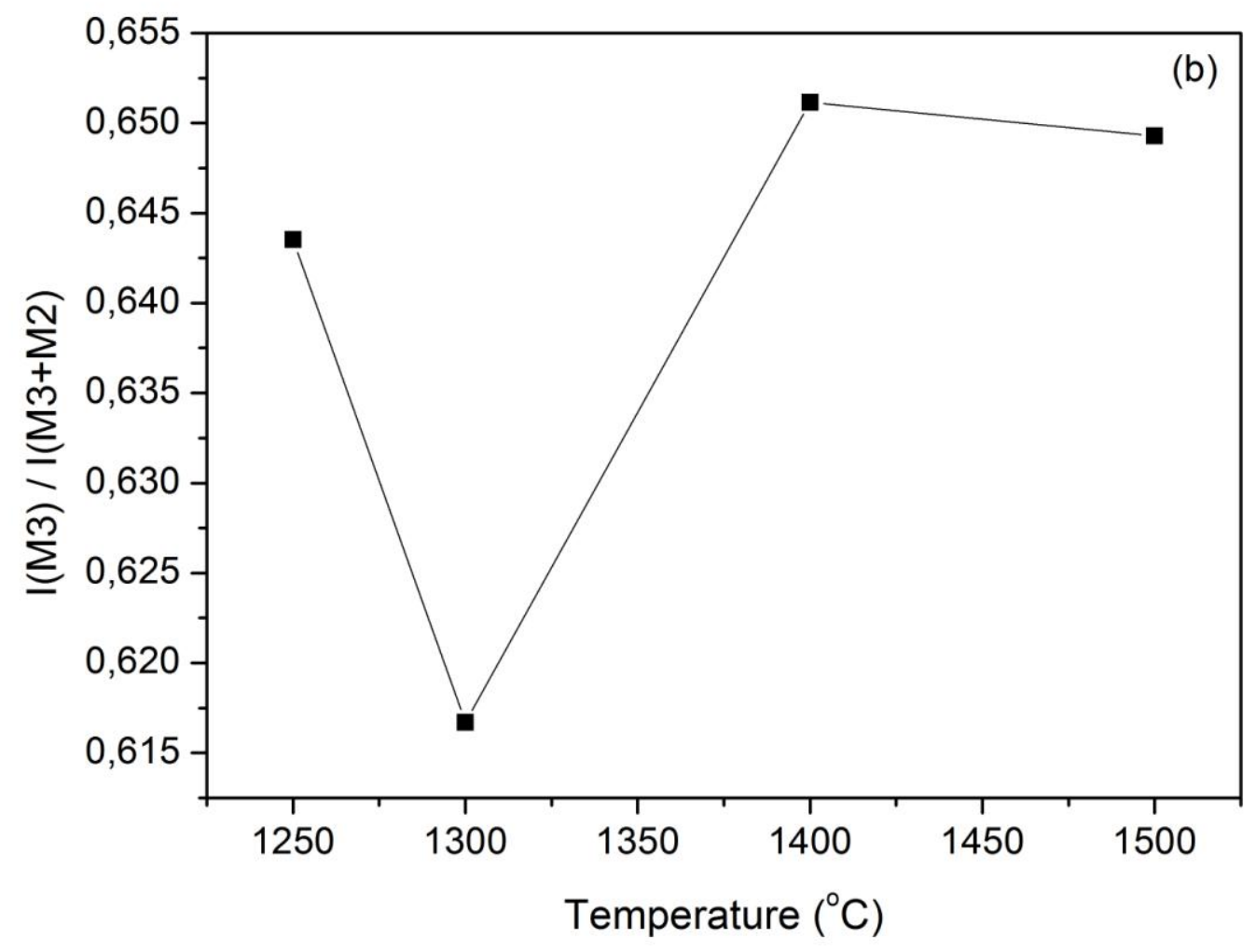




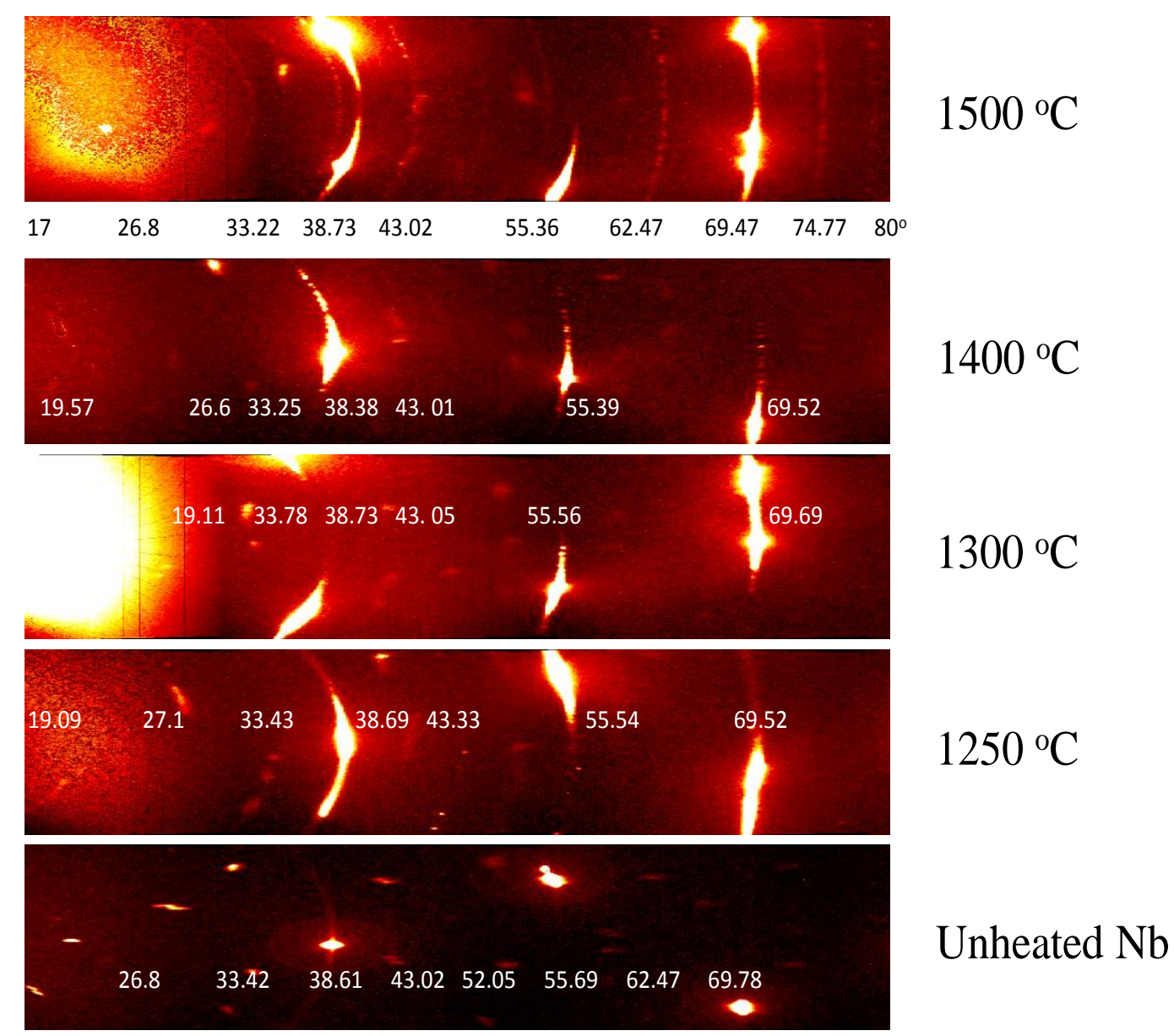

